patient time (and in any event the number of patients is some 160000 a year).

The objective of many of the major projects was to improve the efficiency of medical carethat is, they lead directly to increased quality or quantity of care or reduce the cost. This may be improved by clinical decisions being more soundly based, improved scheduling of patients, improved use of staff time, or better planning and management control. To measure these things requires new methods. These are being developed. This is the first major programme within the Health Service where an attempt has been made at evaluation. We are therefore pioneering the evaluation of health care programmes in general. The evaluation results available to date are in no sense complete and should not be taken as such. You suggest that the only thing that has been measured is the cost of the systems. Most of the projects have produced interim evaluation reports in which a large number of benefits have been highlighted.

While we would agree that there are many small projects (such as computer-aided history-taking and diagnosis) which have been inexplicably excluded from DHSS funding, we reject your opinion that "the only systems likely to pay off in the near future are very simple ones." Our opinion is fully supported by unpublished material available to us. The main advantage of the large project is the potential to co-ordinate the key services of the hospital, enabling efficiency of medical care and scheduling and rationalisation of resources to be improved on a massive scale.

It is also important to note that the cost figures mentioned relate to the costs of prototype systems, and prototype costs are always much higher than the costs of developed systems. This statement is just as true for hospital systems as it is, for example, in the automobile industry.

T J R BENSON Charing Cross Hospital, London W6 Senior Evaluation Office

A D Cundy Senior Evaluation Office

The London Hospital,

London E1

Committee of Public Accounts, Sixth Report (1975 76 Session), p 483. London, HMSO, 1976.

\section{Delusions of parasitosis}

SIR,-Your leading article on this subject (26 March, p 790) does not mention the use of monoamine oxidase inhibitors in the treatment of this condition. It is unfortunate that this group of drugs is almost totally ignored by most doctors. We find that senior medical students coming to the practice have hardly heard of them, yet with careful selection of patients and with due regard to the dietary restrictions they can work near-miracles in patients with severe obsessional states and depressions.

We have a patient now aged 58 who presented with delusions of parasitosis in 1966. She complained of small bugs or worms crawling about in her gums and would bring specimens of the alleged bugs carefully wrapped in tissue paper. We were, of course, never able to see them and as she did not improve with various tranquillisers and antidepressants she was referred to a psychiatrist with a tentative diagnosis of paranoid schizophrenia.
She was given electric convulsion therapy, amitriptyline, trifluoperazine, and chlorpromazine but continued to suffer greatly for the next two years. In April 1968 we put her on Parstelin (tranylcypromine $10 \mathrm{mg}$, trifluoperazine $1 \mathrm{mg}$ ) one tablet four times a day. When seen one week later she was greatly improved. Her delusions disappeared completely and have never returned, though she has continued to have a number of symptoms, particularly abdominal pain which has been fully investigated without a cause being found.

Because she (and we) suffered so greatly when she had her delusions we have not dared to stop the Parstelin, but on reading carefully through her notes to write this letter it seems obvious that it is time for a cautious withdrawal of treatment and this we shall now do, but she will continue to need the support of her monthly visit to see one of us. We just hope she will not revert to coming to our house at all hours with her little packets.

J ROBERTS

Wythenshawe

Manchester

SIR,-Your leading article on this subject (26 March, p 790) gives a good description of a syndrome which, until lately, certainly had a poor prognosis for recovery, as you say. However, the situation appears to be changing and evidence is emerging that this disorder may be particularly responsive to treatment with pimozide (Orap). ${ }^{1}$ Dr J Riding and I have described a good response to this medication in five cases of monosymptomatic hypochondriacal psychosis, two of which presented with delusions of skin infestation. ${ }^{1-3}$ Reilly and Beard have reported confirmation of our findings ${ }^{4}$ and it would seem that patients with delusions of parasitosis form one subgroup within a larger collection of individuals who have delusional beliefs that they smell unpleasantly or have an abnormal appearance or that some other aspect of their anatomy or physiology is deranged, despite all evidence and reassurance to the contrary. A striking feature in these patients is that the personality is otherwise well preserved and there is usually little other evidence of psychosis. Psychiatrists often do not see these patients because they haunt departments of plastic surgery, otorhinolaryngology, tropical medicine, and dermatology. When they are seen in a psychiatric department psychological treatment almost invariably proves of no avail, and until recently drug therapy was equally unhelpful.

Since coming to Canada in 1975 I have treated four further cases of monosymptomatic hypochondriasis, three of them with delusions of infestation, with pimozide, all with good results to the present time. I hope to publish these cases elsewhere in the near future but in the meantime I think it important to point out that there may be a ray of hope for some of these wretchedly miserable patients, whose whole life becomes dominated by a false belief about their health and never-ending search for a cure.

The dose of pimozide required in treatment is usually modest, between 2 and $6 \mathrm{mg}$ per day in most cases given in a single morning dose. At this level side effects are minimal or absent and improvement usually begins within two weeks. It is worth emphasising that pimozide does not appear to work in cases in which the symptoms are at a neurotic as opposed to psychotic level. Patients with dysmorphophobia or similar neurotic illnesses have a fixed belief that there is some serious abnormality of bodily structure or of health, but this belief does not reach a delusional level. It is therefore important to have a psychiatric opinion before starting treatment with pimozide to differentiate between the two types of disorder.

I would be interested to know if any other psychiatrist has had a similar experience with the treatment of cases of delusion of parasitosis. I have now started a clinical trial of pimozide and would be glad to share my experience of the drug's effects.

Alistair MUnRo

Department of Psychiatry, Toronto, Ontario ' Riding, J, and Munro, A, Lancet, 1975, 1, 400.
'Riding, J, and Munro, A, Acta Psychiatrica Scandinavica, $1975, \mathbf{5 2}, 23$.

s Munro, A, British fournal of Psychiatry, 1976, 129 287. Reilly, T M, Beard, A W, British fournal of
Psychiatry, 1976, 129, 191.

SIR,-Your leading article on this subject (26 March, p 790) is of interest, but it is not only doctors and health authorities who are involved: our pest control surveyors are often called upon to placate these unfortunate people. As you have mentioned, the diagnosis must be correct, so our first objective is a thorough survey of the house. If no insects or mites can be found, however, we also are faced with the problem of how to deal with the patient.

Under these circumstances our principle is to refuse politely to undertake any insecticidal treatment. A placebo or even a genuine treatment for some quite unrelated infestation is rarely successful; we simply have to make expensive call-backs. Our surveyor then suggests that where no insects can be found the patient may have developed a "skin allergy" and a visit to the doctor may help. The word "allergy" appears to be sufficiently well known to be acceptable by most people, even if they are suspicious of doctors.

It is to be hoped that general practitioners are aware of delusory parasitosis and able to identify this condition. Ebeling ${ }^{1}$ suggests that marital problems constitute a major cause, a factor that may be worth bearing in mind when attempting to formulate a course of treatment. An added difficulty arises when the sufferer persuades her husband that he too is "parasitised"; the doctor may then find himself seeing the wrong patient.

Perhaps of interest is the American woman who forced her entire family to bath in petrol and rub with sulphur and lard every dayalmost guaranteed to produce a skin reaction.

ROBIN EDWARDS

Research and Development Division,

Rentokil Ltd,

East Grinstead, Sussex

Ebeling, W, Urban Entomology. Berkeley, University of California Division of Agricultural Sciences,

\section{Detection of bone metastases}

SIR, - The real value of radioisotope scanning as the most effective method for detecting bone metastases appears now to be gaining general acceptance. I am sure that many radiologists 
would agree that the alternative investigation, a skeletal survey, is more time-consuming and expensive and considerably less accurate. What a shame, therefore, that in attempting to compare these two methods Dr S J Williams and his colleagues (16 April, p 1004) base their conclusions upon such poor evidence.

Not only did they restrict their routine scans to the spine, pelvis, and upper femora (and therefore almost certainly missed lesions in the skull and ribs) but in only six of the 44 patients whom they considered to have definite metastases did histological evidence become available. We are also told that 21 patients were assigned to this group on the basis of their bone pain, and yet from the figures it is apparent that an almost equivalent number of patients with similar symptoms were thought to be free of metastases. Surely they must be aware that the severity of pain (which must be extremely difficult to assess) is no guide to the presence of disease, as evidenced by the frequent demonstration of occult painless metastases.

Nevertheless I am sure that, however unsupported, their general conclusions on the value of isotope bone scanning are correct. The more effective demonstration of metastases may certainly affect the management of such patients, but does it, I wonder, ever affect their prognosis ?

NeIl Garvie

Isotope Department,

Royal Marsden Hospital,

London SW3

\section{Raised mean cell volume and Mycoplasma pneumoniae infection}

SIR,-I read with interest the report by Dr Peter Kopelman (2 April, p 881) of a case of Mycoplasma pneumoniae infection in which the diagnosis was suspected owing to a raised mean cell volume (MCV) in the Coulter $S$ counter.

In our laboratory we have found that a raised $\mathrm{MCV}$, together with an abnormally raised mean corpuscular haemoglobin $(\mathrm{MCH})$, is almost diagnostic of the presence of cold agglutinin, whether specific or non-specific. In all cases we have noticed macroscopic or microscopic autoagglutination of red cells. The same sample of blood when put through the Coulter $S$ after warming to $37^{\circ} \mathrm{C}$ shows a significant reduction in the $\mathrm{MCV}$ and $\mathrm{MCH}$ together with a rise in total red cell count.

\section{R R KHAUND}

Department of Haematology, City Hospital
Aberdeen

\section{Gross oedema during treatment for depression}

SIR,-With reference to the case report by Drs A Goonewardine and P J Toghill (2 April, p 879) I wish to report a similar case seen in general practice.

The patient, aged 61 and disabled, has been suffering from depressive psychosis for several years and has received several psychotropic drugs, including impramine, amitriptyline, a monoamine oxidase inhibitor (MAOI), and various tranquillisers and sedatives in different strengths and combinations. Last August he was prescribed isocarboxazid $10 \mathrm{mg}$ twice a day increasing to a total dosage of $30 \mathrm{mg}$ daily. Along with this he was also given a combination of amitriptyline $25 \mathrm{mg}$ and chlordiazepoxide $10 \mathrm{mg}$ (Limbitrol) two capsules at night. He religiously followed the dietary restrictions necessary for MAOIs. Within two weeks of the start of this treatment he showed signs of massive oedema from the ankles up to the thighs. His blood pressure was $110 / 70 \mathrm{~mm} \mathrm{Hg}$.

There was no sign of any other disease to account for this oedema. All the investigations were reported as normal. The isocarboxazid was withdrawn and he was given injections of frusemide $80 \mathrm{mg}$ intramuscularly (supplemented with the usual oral potassium) for four days and then switched over to $120 \mathrm{mg}$ of frusemide daily by mouth. His oedema disappeared within a week and he has been free of any ankle or leg swelling since then.

Romford, Essex

S K PATHAK

\section{Test antiserum for group $B$} meningococci

SIR,-In your leading article on "Partly treated pyogenic meningitis" (5 February, p 340) you state that satisfactory test antisera for group B meningococci are not available. May I refer you to a recent article by Semgen et $a l^{1}$ in which it is reported that Escherichia coli $\mathrm{K} 1$, the capsular polysaccharide similar if not identical to the meningococcal B group antigen, is readily detected by an equine meningococcal group B globulin.

This antiserum was prepared by the repeated intravenous injection of formaldehyde-treated group B meningococci, strain B-II, by wellknown methods for the production of diagnostic antisera. Horse serum gives adventitious precipitin reactions in agar gel with the buffe systems commonly employed for countercurrent immunoelectrophoresis. Accordingly the serum fraction precipitated between $34 \%$ and $50 \%$ saturated ammonium sulphate and then exhaustively dialysed against $0.05 \mathrm{M}$ $\mathrm{NaCl}$ and centrifuged clear is used.

Division of Bacterial Products,

JOHN B ROBBINS

Bureau of Biologics,

Food and Drug Administration, Bethesda, Maryland

'Semgen, G, Ørskov, I, and Ørskov, F, Acta Patholo gica et Microbiologica Scandinavica, Section B,
$1977,85,103$.

\section{"Insects and history"}

SIR,-The review of my book Insects and History (26 March, p 849), although generally quite favourable, nevertheless criticises it unjustly in two respects.

The reviewer states: "The interpretation of fevers, agues, plagues, and other epidemic diseases of the past is a fascinating problem but perhaps not so easily undertaken as the author indicates." On p 35 of the book, however, I have written as follows: "Especially with old records, it is almost impossible to determine with any certainty what disease was actually involved, whether there were one or more epidemics raging concurrently and to what extent the various plagues exerted a direct effect by destroying man and supplies, or an indirect effect through men's minds." Later in the review we read: "The impression is created that a fever from the past was mosquito-borne and that flies were responsible for fluxes, cholera, and dysentery. This is a real weakness in the book. ..." Yet throughou I have stressed the point that fevers only may have been caused by particular pathogens. For instance, even in the introduction I write: "Hannibal was halted in Syracuse by the inroads of bubonic plague, smallpox or malaria among his troops." On p 131 your reviewer could have seen the following: "Surely one of the most terrifying of all diseases, cholera, like typhoid, is spread in epidemic form largely by contaminated water, but flies may also play a part in its transmission"; or on p 140, "Most often, dysentery resulted from taking contaminated water on board ship, but no doubt the innumerable flies, breeding in the filthy bilges of wooden ships, would have contributed to the spread of the disease."

It is a serious weakness of the review that its author cannot have given my book much more than a cursory glance before penning these criticisms.

J L CloudsLey-Thompson

Department of Zoology,

Birkbeck College,

Gluten-free diet in dermatitis herpetiformis

SIR,-We were interested to read the paper by Drs Christine I Harrington and N W Read (2 April, p 872) on the effects of a gluten-free diet (GFD) in dermatitis herpetiformis. However, we were disturbed to see that they attribute to us a report of "no significant difference in the reduction of the dose of dapsone between patients on a gluten-free diet and a control group of patients on a normal diet." In fact our own paper ${ }^{1}$ indicated quite the converse-a greater reduction in dose was clearly established in our GFD-treated patients. In addition, more of our GFDtreated patients than controls were able to cease drug therapy altogether, although this difference was not statistically significant. Nevertheless, the benefits of the diet with respect to drug dosage were unequivocal.

The observations by Drs Harrington and Read thus broadly confirm our own experience and we share with them a belief that GFD treatment is of value in dermatitis herpetiformis. However, the assessment of individual patients remains difficult. While reduction in medication is certainly a definable goal, common sense indicates that a highly motivated patient who subjects himself to the inconvenience of a GFD hoping for a reduction in his drug requirements is likely to do all he can to convince himself (and thus his physician) that he is succeeding. In these circumstances apparent reductions in drug dosage are likely to overestimate the benefits of the diet, and their use as "a yardstick against which to gauge progress" may be misleading.

Drs Harrington and Read make several statements about the effect of a GFD on the jejunal mucosa of their nine patients without apparent regard for the reported patchiness of the small-bowel abnormality in dermatitis herpetiformis. ${ }^{2}$ It remains to be shown that improvement in the jejunal mucosa of individual patients may be reliably assessed from Crosby-capsule biopsy specimens and thus an assertion that any individual patient shows improvement is questionable if it is based on single biopsies before and after treatment. At present, it seems that multiple 